\title{
Contribution to the French program dedicated to cementitious and clayey materials behavior in the context of Intermediate Level Waste management -Hydrogen transfer and materials durability
}

\author{
B. Bary, P. Bouniol, L. Chomat, W. Dridi, C. Gatabin, C. Imbert, V. L’Hostis, P. Le Bescop, \\ B. Muzeau, S. Poyet
}

CEA Saclay, CEA, DEN, DPC, SECR, Laboratoire d'Etude du Comportement des Bétons et des Argiles, F-91191 Gif-sur-Yvette, France

\begin{abstract}
This article illustrates a contribution of the CEA Laboratory of Concrete and Clay Behavior ("LECBA") for the assessment and modeling of the Long-Term behavior of cementitious and clayey materials in the context of nuclear ILW (Intermediate Level Waste) management. In particular, we aim at presenting two main topics that are studied at the Lab. The first one is linked to safety aspects and concern hydrogen transfer within cementitious as well as clayey materials (host rock for French nuclear waste disposal). The second point concerns the assessment of durability properties of reinforced concrete structures in the disposal (pre-closure and post-closure) conditions. Experimental specific tests and phenomenological modelling are presented.
\end{abstract}

\section{Introduction}

ILW comprises a variety of materials with different characteristics [1]. Such wastes generally arise due to direct contamination with actinides and the products of nuclear fission, or due to neutron activation of otherwise non-radioactive materials (materials contaminated with fission products and actinides arising from the reprocessing of spent nuclear fuels (e.g. fuel cladding), components of nuclear reactors such as the moderator (e.g. graphite in some core designs), control rods and any incore instrumentation activated through processes of neutron capture, filters and ion exchange materials used to capture solid corrosion products and dissolved radionuclides (e.g. Cs-137) released during fuel irradiation in reactor or during post-irradiation cooling in water ponds (e.g. ion exchange resins), various substances arising from industrial or medical applications and research and development activities. A recent review of concepts for deep disposal of ILW is available in [2]. Where required, ILW is immobilized in a solid waste form and packaged in a waste container. The combination of a waste form and a waste container is usually termed waste package. Cement and bitumen are often employed as encapsulation materials, although other materials are also considered (e.g. epoxy resins, glasses).

There are technical issues which are specific to the management and disposal of ILW. Such issues tend to be associated with the variety and chemical nature of ILW waste streams and with the nature and timescales of waste management operations envisaged for these materials. Specific issues which are discussed in this work include: 
- The potential for significant gas generation due to radiolysis of the nuclear waste embedded in cement-based matrix, or due to corrosion of the specific metals typically present in the waste (e.g. steels, aluminium, magnesium alloys). Depending on package design, waste packages for gasgenerating ILW may or may not incorporate engineered vents to allow the gas to be released. If significant gas generation is expected and no engineered vents are used, it may be important to demonstrate that any pressurisation of the waste packages is unlikely to affect their functionality, especially during any pre-disposal period. After disposal in a waste repository (post-closure period), it is also important to evaluate the potential for generation of large quantities of non-radioactive gases (e.g. hydrogen), since this may facilitate the formation of leak paths for radioactive gases, affecting the performance of engineered and natural barriers in the repository.

- The potential for significant degradation of waste packages during periods of storage in surface facilities and for the operational period of waste repositories (defined as the pre closure period), since packaging of some ILW has commenced few decades ago and it is likely to take many further decades before a repository becomes available and such packages finally disposed with an appropriate backfill. Limiting the potential for further degradation during the operational period is important to ensure reversibility of emplacement operations (if this is required) and to ensure that waste packages enter the post-closure period in a good condition. A key issue for ILW is that the environmental conditions (e.g. temperature and relative humidity) during periods of storage and operations of a waste repository are likely to be affected by the evolution of the external environment (i.e. cyclic). Degradation of waste packages are also to be considered during the pre closure period that will occurs in a clayey geological layer in France.

\section{Gas generation and transfer}

\subsection{Gas transfer in cementititous materials}

Gas transfer within cementitious materials is studied at the Lab in the context of cementitious waste packages radiolysis [3]. As transfer properties are influenced by the microstructure of materials and by relative humidity $(\mathrm{RH})$ of atmosphere, specific tests are conducted for dedicated materials in different RH. For high RH, a great discrepancy of diffusion properties is observed as the diffusion coefficient differs from three orders of magnitude between 85 and 95\% (Figure 1a).

Modeling strategy has allowed explaining this discrepancy with the use of multi-scale homogenization tools, previously developed for liquid diffusion [4]. Considering that the water film is adsorbed on the surface of the pores, condensation in little pores can happen or not, depending on the theory of stable or unstable films (Figure 1b). Calculations carried out with both theories are consistent with the experimental data (Figure 1a).

At this moment, the PhD study of B. Larbi [5] aims at improving this topic by taking into account of the Interfacial Transition Zone (ITZ) present at the sand / cement paste interface in a mortar. 


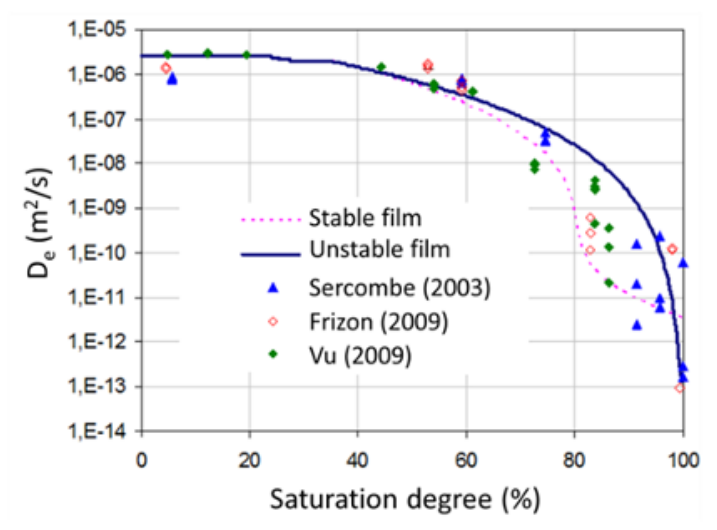

(a)

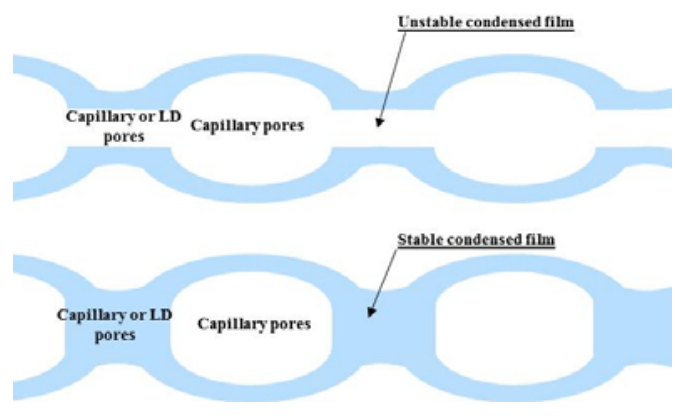

(b)

Fig. 1. a) Experimental values of hydrogen diffusion coefficient measured for different RH (CEM I cement type) and modelling result considering stable or unstable films within porosity (b).

\subsection{Gas transfer in clayey materials}

After disposal in the waste repository (post-closure period) that should be in a clayey geological layer in France, studies are conducted in order to evaluate the potential for generation of large quantities of hydrogen. Two specific experiments are conducted at the Lab in order to evaluate hydrogen transfer in the natural clayey material and also in bentonite bricks.

The ARGAZ experiment consists of a metallic electrode that is embedded in a clayey confined material. Hydrogen is generated by electrochemistry as the nickel electrode is the counter electrode where the water reduction takes place and is rely on an iron electrode that plays the role of anode (Figure 2a). At this moment, a corrosion rate of $3 \mu \mathrm{m} /$ year is mimicked. Pressure sensors results show that the diffusion of $\mathrm{H}_{2}$ is under dissolved form only. The corrosion rate will soon be increased up to $6 \mu \mathrm{m} /$ year.

The BENTOGAZ experiment is constituted of 2 vessels (upstream (high pressure) and downstream (low pressure)) that are separated by a bentonite block saturated with water (Figure $2 \mathrm{~b}$ ). Preliminary results show that a light but progressive increase of the downstream pressure is observed due the diffusion of the gas injected within the clayed plug. This increase continues until a certain upstream pressure, 30\% above swelling pressure of bentonite, (breakthrough pressure), then a rapid transfer of gas in the downstream is noticed. Immediately after the upstream vessel is drained under swelling pressure, bentonite seals the pathway of gas. If this result is confirmed, this would mean that in case of increasing pressure due to gas generation (from anaerobic corrosion or from radiolysis) the bentonite block would keep its sealing quality after the release of the excess of pressure. 


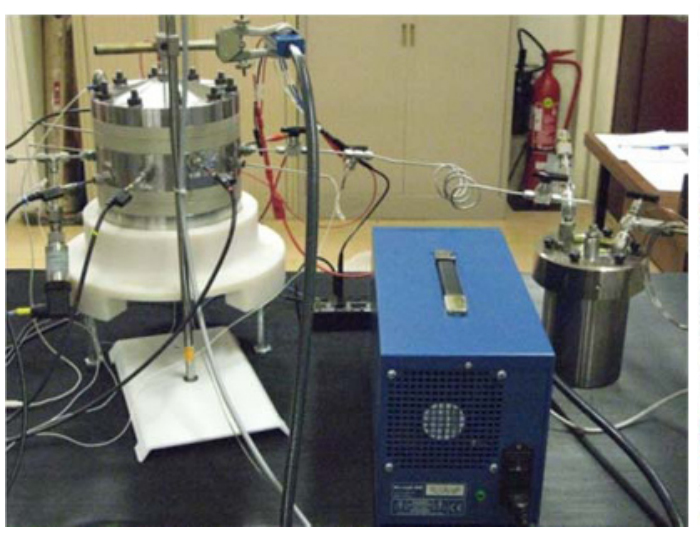

(a)

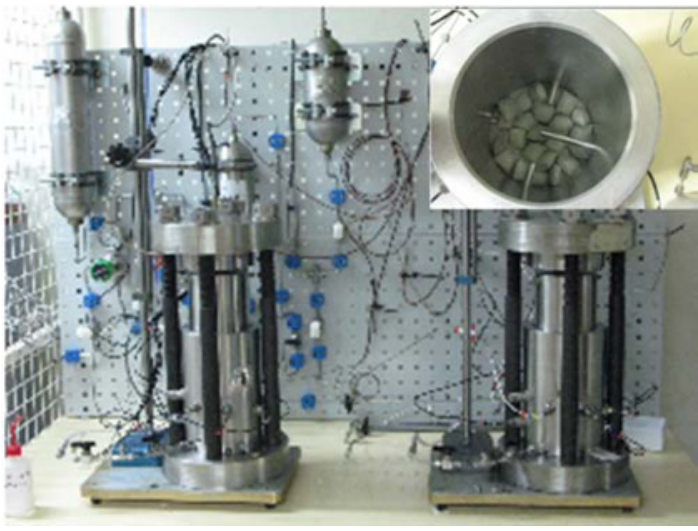

(b)

Fig. 2. a) ARGAZ experiment and b) BENTOGAZ experiment.

\section{Durability of reinforced concrete structures}

\subsection{Chemo-transport-mechanical couplings}

Process and modeling the chemical degradation of concrete due to aggressive species presents in the clayed geological medium is a subject of main concern in the Lab since 20 years. First, the elementary effect of sulphates, carbonates and $\mathrm{pH}$ value was considered.

Sulphate attack has been experimentally evidenced [6] and then modeled considering a simplified chemo-mechanical coupling approach including damage initiation and growth [7].

Chemical degradation of concrete due to carbonates has been studied in specific reactors able to manage $\mathrm{pH}$ with $\mathrm{CO}_{2}$ additions, without introducing new anions in the system [8]. The degradation front, characterized by a depletion of the portlandite and the precipitation of calcite has been evidenced. Thus a phenomenological modeling based on chemo-transport processes has been proposed [9].

The effect of $\mathrm{pH}$ of the solution has been also considered. A specific modeling including chemistry, transport and mechanical aspects has been developed [10]. This model, implemented in the software ALLIANCES (coupling chemical, transport and mechanical codes), is able to predict in the case of leaching the degradation fronts of minerals, the evolutions of the diffusion properties of the degraded zone and its Young's modulus (Figure 3) as a function of the mineral assemblage thanks to multiscale homogenization techniques. Macroscopic cracking is also described by a specific orthotropic damage model [11]. 


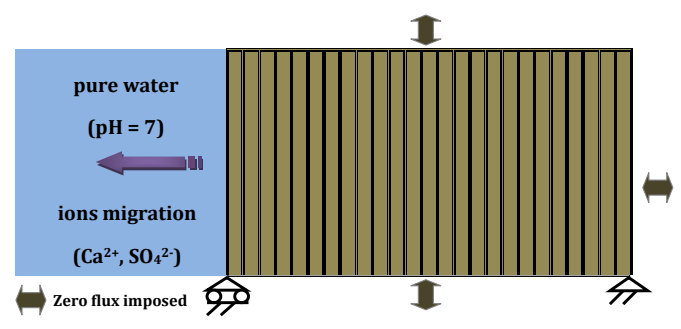

a)

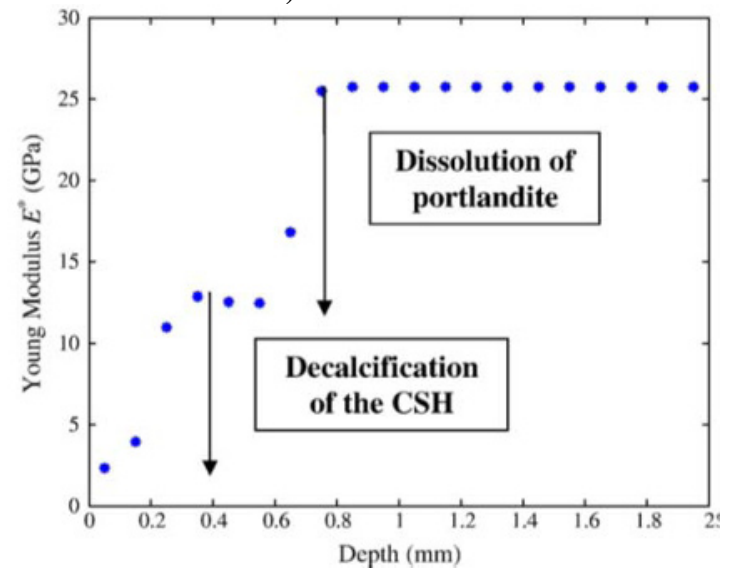

c)

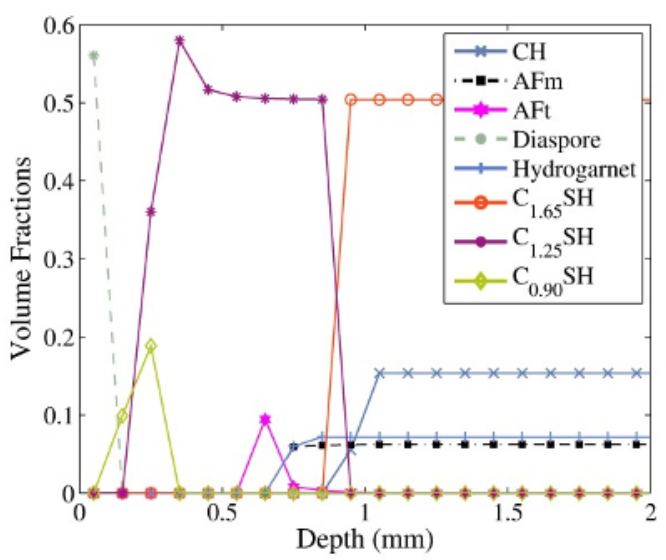

b)

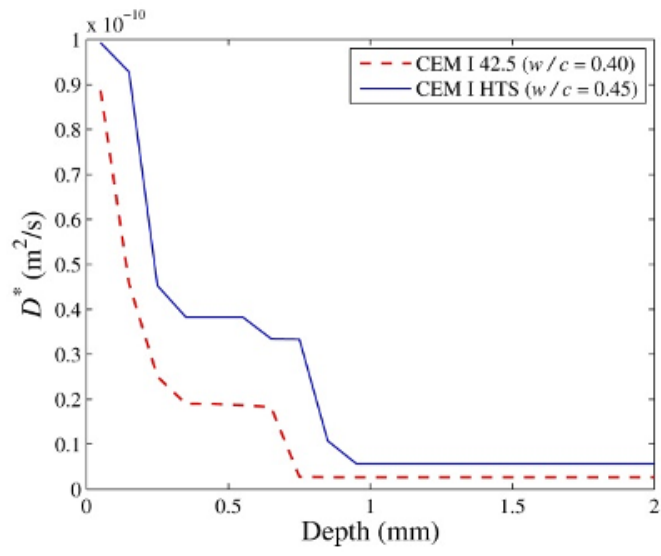

d)

Fig. 3. a) Schematic of the one-dimensional system employed for the simulations of pure water leaching of cement paste sample (ALLIANCES software), calculations for 50 days test [11],

b) Mineral compositions in terms of volume fractions inside a sample of CEM I 52.5 HTS paste (High Silica Content) with w/c $=0.45$ at 50 days,

c) Evolution of the Young modulus inside a sample of CEM I 42.5 paste with w/c $=0.40$ at 50 days,

d) Evolutions of the diffusivities predicted with the multi-scale homogenization model inside samples of CEM I $42.5(\mathrm{w} / \mathrm{c}=0.40)$ and of CEM I HTS $(\mathrm{w} / \mathrm{c}=0.45)$ pastes.

At this moment, tests and modeling approach are realized for more realistic conditions. Cementitious materials are exposed to a solution representative of the clayey geological layer (multi-ionic attack) or directly to the natural clay (specific device ABIE able to keep the confinement of clay in contact with cement paste) (Figure 4a). In particular, the $\mathrm{PhD}$ study of A. Dauzères [12] allowed to show that transport properties of the degraded zone are altered, due to the clogging of the porosity linked to the precipitation of calcite (Figure $4 \mathrm{~b}$ ). 


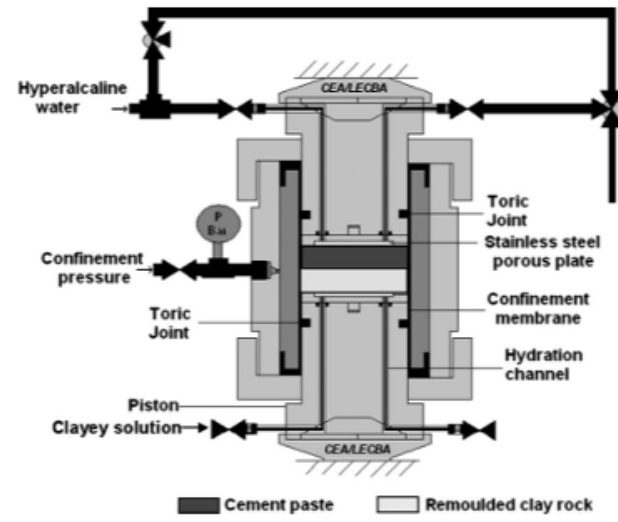

(a)

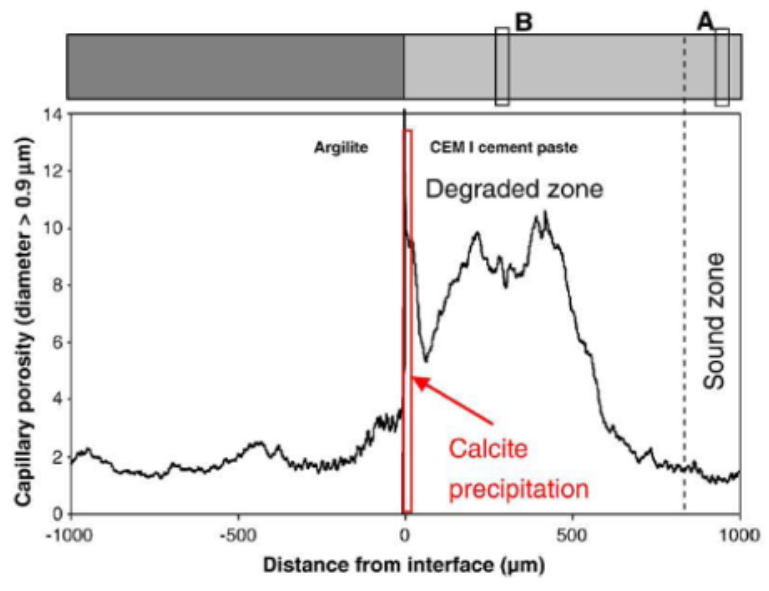

(b)

Fig. 4. a) ABIE specific device developed for contact between cementitious and clayey materials,

b) Macroporosity profile calculated by image analysis from X-ray tomography measurements (1 yr test) [12].

\subsection{Passive reinforcement corrosion}

Most of the concrete structures built in the disposal site will be reinforced with steel bars. Question is asked if passive corrosion of rebars can be guarantee for very long periods. Studies have been conducted in the Lab in order to assess conditions where passive corrosion takes place, in aerated as well as in deaerated conditions. Experimental results allowed proposing that passive corrosion state is obtained in deaerated conditions from pH 12.6 to pH 9.9 (Figure 5a). Passivity has been pointed out for steel embedded in mortars exposed to different relative humidities (until 5 years) and a solution representative of a clayey geological layer [13]. In aerated conditions, depassivation of steel can occurs at pH between 10 and 9.4 depending on chemical species in solution (sulphates, silicates and carbonates) [14] (Figure 5b).
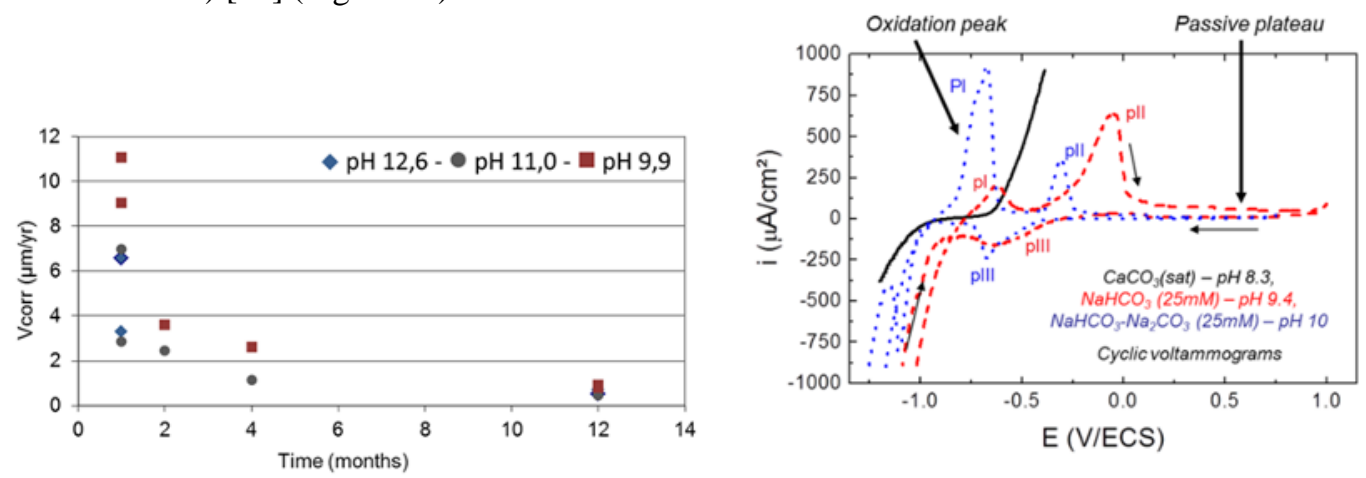

Fig. 5. a) Corrosion rates from gravimetric measurements in deaerated solutions from $\mathrm{pH} 12,6$ to $\mathrm{pH} 9,9$ [13]; b) Polarization curves plotted for steel immersed in solutions from $\mathrm{pH} 10$ to $\mathrm{pH}$ 8,3 [14].

Present studies are focusing on the effect of additions in cementititous materials on the passive corrosion behavior of steel. 


\subsection{Thermo-hydro-mechanical couplings}

The experimental characterization of the Thermo-hydro-mechanical (T-H-M) coupled behaviour of concrete and clayey (natural and bentonite) materials is studied since 20 years in the Lab.

We can mention the study of Poyet [15] that showed the effect of temperature on water sorption properties in cementititous materials porosity. Concerning clay materials, specific devices have been developed in order to assess the evolution of water permeability with the capillary pressure (Figure 6) [16].

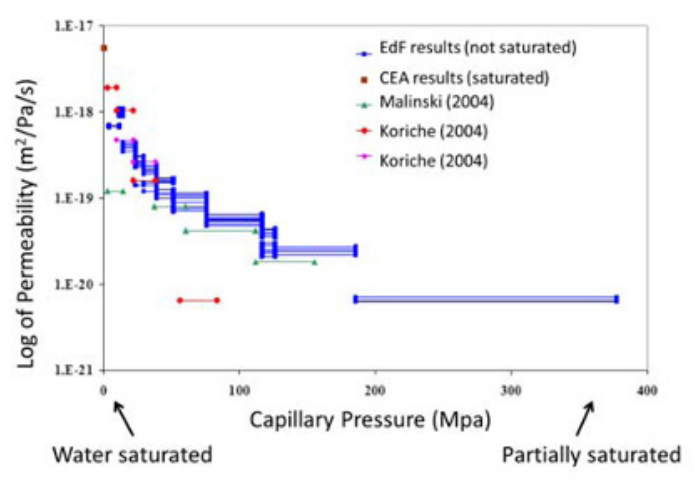

(a)

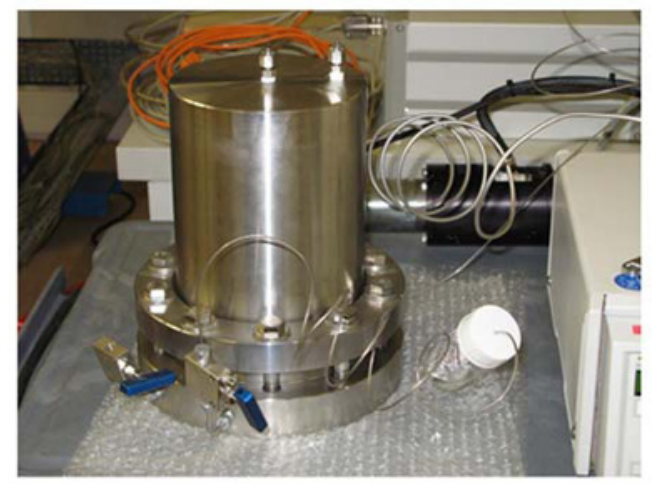

(b)

Fig. 6. a) Relation between permeability and capillary pressure in clay materials [15], b) Specific device develop for tests in water saturated conditions.

A phenomenological simplified model has been developed for T-H-M applications. This THMs model is based on the mechanics of partially saturated porous media and assumes that the gaseous phase is composed exclusively of vapor [17]. This hypothesis leads to substantial simplification in the theoretical formulation since only one equation governs the mass conservation of the water in both liquid and gas form.

It has been implemented in the finite element code Cast3M developed at CEA, and applied to the simulation of a reinforced concrete structure MAQBETH. This structure is constituted of a hollow cylinder with external diameter of $2.2 \mathrm{~m}$ and height of $3 \mathrm{~m}$, and it has undergone a thermal loading at $200^{\circ} \mathrm{C}$ in the inner surface during several hundreds of hours (Figure 7 ).

The model capacity to reproduce the main features of the concrete structure including the reinforcement rebars has then been demonstrated through the comparison between numerical and experimental results in terms of evolutions of temperatures, gas pressures, relative humidity and strains in the median plan of the structure as a function of time [18]. Note that the simulation has been carried out in 2D on 2 different meshes adapted for solving the thermo-hydric and mechanical problems, respectively, in an axisymmetric formulation (Figure 7). 


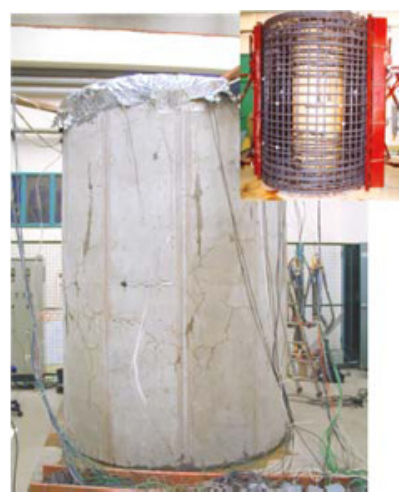

(a)

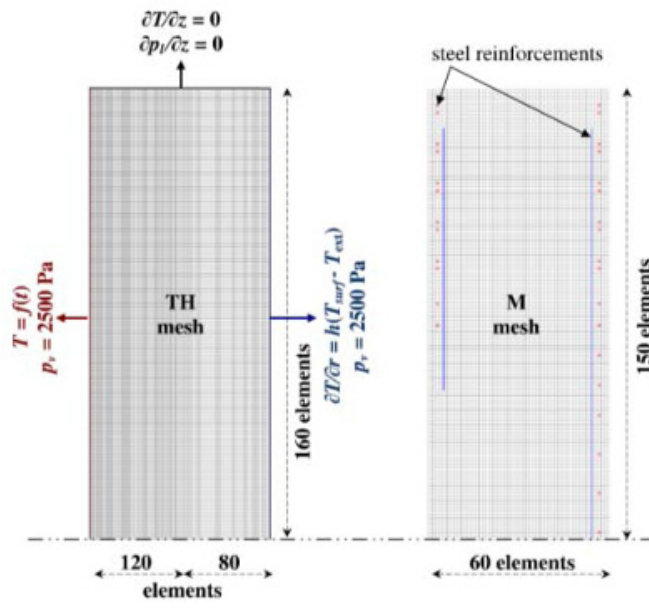

(b)

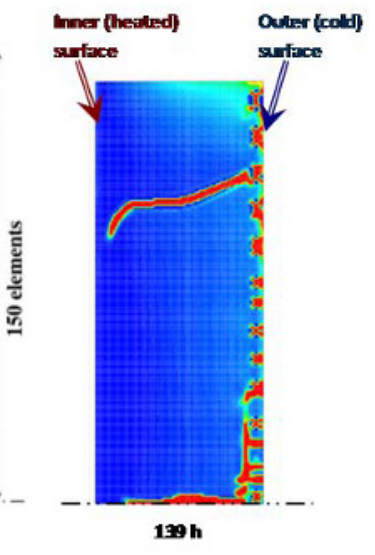

(c)

Fig. 7. a) General view of MAQBETH mock-up and cylindrical steel reinforcement, b) Thermo-hydric (left) and mechanical (right) 2D meshes with boundary conditions, c) Numerical damage patterns in the upper part of the structure after $139 \mathrm{~h}$ of heating [17].

\section{Conclusion}

This paper aimed at illustrating the R\&D approach developed at the Lab in the context of nuclear ILW (Intermediate Level Waste) management. At this moment, studies are focusing on the effect of chemistry of cement on durability and transfer properties (cement containing blast furnace slag and fly ashes). The main other aspect concern the early age behaviour of cementititous and clayey materials (bentonite) and its relation with the long term properties, including conditions of building the structures and early age mechanical stresses that would create cracks in concrete vault. The Lab is also involved in the programmes dedicated to demonstration of feasibility of nuclear waste disposal structures (bentonite and concrete formulations).

\section{References}

1 Organisation for Economic Co-operation and Development, Nuclear Energy Agency, Advanced Nuclear Fuel Cycles and Radioactive Waste Management, OECD Publishing, ISBN: 9789264024854 (2006).

2 T.H. Hicks, T.D. Baldwin, P.J. Hooker, P.J. Richardson, N.A. Chapman, I.G. McKinley and F.B. Neall, Concepts for the geological disposal of intermediate-level radioactive waste, Galson Sciences 0736-1 (2008).

3 P. Bouniol, E. Bjergkakke, Journal of Nuclear Materials, Vol. 372 (1), pp. 1-15 (2008).

$4 \quad$ W. Dridi, Materials and Structures (in press) (2013).

5 B. Larbi, W. Dridi, P. Le Bescop, P. Dangla, L. Petit, NUCPERF 2012 proceedings (2013).

6 D. Planel, J. Sercombe, P. Le Bescop, F. Adenot, J.M. Torrenti, Cem. Conc. Res. 36, pp. 137143 (2006).

7 B. Bary, International Journal for Numerical and Analytical Methods in Geomechanics, vol. 32, pp. 1791-1816 (2008).

8 L. Chomat, P. Le Bescop, N. Meddahi-Trep, C. Galle, X. Bourbon, 13th International Congress on the Chemistry of Cement (ICCC - 2011), 650p. (2011). 
9 A. Dauzères, P. Le Bescop, P. Sardini, C. Cau Dit Coumes, 6th international conference on Concrete under Severe Conditions (CONSEC'10), Castro-Borges et al. (eds), 792p (2010).

10 E. Stora, B. Bary, Q.-C. He, E. Deville, P. Montarnal, Cem. Conc. Res. 39, pp. 763-772 (2009).

11 E. Stora, B. Bary, Q.-C. He, E. Deville, P. Montarnal, Cem. Conc. Res.. 40 , pp. 1226-1236 (2010).

12 A. Dauzeres, P. Le Bescop, P. Sardini, C. Cau Dit Coumes, Cem. Conc. Res., 40, pp. 13271340 (2010).

13 V. L'Hostis, E. Amblard, C. Blanc, F. Miserque, C. Paris and L. Bellot-Gurlet, Corrosion Engineering, Science and Technology, Vol. 46 (2), pp. 177 (2011).

14 B. Huet, V. L'Hostis, F. Miserque, H. Idrissi, Elec. Acta, Vol. 51 (1), pp. 172-180 (2005).

15 S. Poyet, S. Charles, Cement and Concrete Research, 39 (11) pp. 1060-1067 (2009).

16 P. Sémété, C. Imbert, P. Desgree, B. Février, A. Courtois, G. Touzé Thermo-Hydromechanical and Chemical Couplings in Geomaterials and Applications. Proc. Of the 3rd Int. Symp. GeoProc’2008. J.-F. Shao \& N. Burlion eds, Wiley (2008).

17 B. Bary, S. Durand, G. Ranc, O. Carpentier, Int. J. Heat Mass Transfer; 51:28, pp. 47-62 (2008).

18 B. Bary, M.V.G. de Morais, S. Poyet, S. Durand, Engineering Structures. 36, pp. 302-315 (2012). 